\title{
AGERGAMIENTO A LUCÍA BOSÉ A TRAVÉS DE LAS OBRAS DE MIGHELANGELO ANTONIONI Y JUAN ANTONIO BARDEM
}

\author{
Endika Rey \\ Universidad Pompeu Fabra
}

\section{INTRODUCCIÓN}

Aunque Richard Dyer afirma que, en términos sociológicos, "las estrellas no existen fuera de los textos, son estos los que deben ser estudiados (...) y sólo se pueden entender y asimilar en referencia a la especificidad de lo que son: principalmente significantes" (2001: 12), también habla de una "imagen generalizada del estrellato que puede verse como una versión del sueño americano, organizada alrededor de los asuntos de consumo, éxito y notoriedad" (2001: 56). El amor, el matrimonio y el sexo son constantes de esta imagen.

Lucía Bosé, nacida en Milán el 28 de enero de 1931, tiene una trayectoria como actriz de más cincuenta años y ha trabajado en más de treinta películas junto a varios de los grandes directores europeos de la época. Sin embargo, en España (donde reside desde hace varias décadas) es más recordada por su relación con Luís Miguel Dominguín que por su cine. Ella misma afirmaba ser consciente de que "lo malo es que pasaré a la historia como mujer de un famoso torero. Ésa será mi inmortalidad" (Olano, 1974: 333). El estrellato por encima de la estrella.

Lo cierto es que su talento interpretativo, correcto y magníficamente explotado, dista mucho de reunir un estilo particular que impregne todas sus películas mediante la familiaridad. Bosé no es Anna Magnani; ni siquiera es Monica Vitti. Su imagen en pantalla no define la esencia última de sus películas, pero sí cumple, por ejemplo, con ese rasgo inherente al estrellato que es la constancia del amor como experiencia metafísica promovida por las revistas de corazón.

En este sentido, Lucía Bosé avanzó por un itinerario propio de ese sueño americano del que habla Dyer. Tal y como cuenta en sus memorias (Aranguren, 2003: 40-44) un día, cuando trabajaba de dependienta de una pastelería milanesa, un cliente se fijó en ella y le dijo "Acuérdese de mí, un día usted hará cine"; el cliente era el mismísimo Luchino Visconti. Poco más tarde, unos amigos la inscribieron en el concurso de Miss Italia, sin que ella hubiese dado 
permiso y acabó ganando el certamen ${ }^{1}$. Tres años después la actriz abrazaría definitivamente la movilidad social ("cualquiera puede ser una estrella") debutando en el cine con Non c'è pace tra gli ulivi (1950), de Giuseppe de Santis.

Tras este primer paso por el neorrealismo, Bosé protagonizaría el debut de Antonioni en la dirección de largometrajes con Crónica de un amor (Cronaca di un amore, 1950) así como la segunda película del director, La señora sin camelias (La Signora senza camelie, 1953). En 1955 , tras varios filmes que la convirtieron en una de las actrices más populares del cine italiano, viajaría a España para rodar Muerte de un ciclista (Juan Antonio Bardem, 1955) y a Francia para filmar Así es la Aurora (Cella s'appelle l'aurore, 1956) junto a Luís Buñuel. Esta película marca el final de una etapa: ya casada con Dominguín, Bosé se retira del cine y no volverá a protagonizar una película hasta separarse.

El artículo no se propone realizar un análisis exhaustivo de la filmografía de Lucía Bosé ni de su potencial condición de estrella. Tal como afirma Dyer, son los textos los que deben ser estudiados, de ahí que hayamos escogido dos de los filmes más representativos de la primera parte de la carrera de Bosé: Crónica de un amor y Muerte de un ciclista. Ambas películas nos permiten acceder a ese carácter transnacional de la figura de la actriz a través de dos filmes-reflejo que, si bien presentan diferencias sustanciales a varios niveles (narrativos, sociales, autorales y de producción) comparten similitudes más allá de su protagonista. A medio camino entre ambos, La señora sin camelias nos permitirá acercarnos mejor a una postura bisagra que habla tanto de la interpretación como de la intérprete.

\section{CRÓNICA DE UN AMOR}

Lucía Bosé es Paola, una joven casada con un millonario milanés. Éste contrata a un policía para que investigue su pasado y a través de sus pesquisas descubrimos que ella y Guido, su ex novio, pudieron haber estado involucrados en la muerte de una amiga. Cuando Guido descubre que les están investigando viaja a Milán para avisar a Paola y es entonces cuando su romance revive. Ella convence a Guido de matar al marido para poder estar juntos de nuevo, pero cuando él está a punto de llevar el homicidip a cabo, éste acaba muriendo en un accidente de coche (que podría ser un suicidio). Igualmente, los amantes se separan y Guido abandona a Paola, que se ha ido quedando progresivamente sola a lo largo de la película. ${ }^{2}$

Crónica de un amor cuenta con una "polarización fuertemente estilizada de dos figuras empequeñecidas por la estructura espacial en que se inscriben" (Bou, 2002: 112). Antonioni usa los planos generales, los largos movimientos de grúa y los espacios vacíos con esta intención a lo largo de todo el filme ${ }^{3}$, pero hay una secuencia de distanciamiento en plano medio que se descubre especialmente significativa: Paola y Guido están en la cama de la habitación de este último. Él se da cuenta de que ella ha perdido un pendiente tras mantener relaciones

1 "En 1947, año en el que a mí me nombraron Miss Italia, Gina Lollobrigida se había presentado al concurso y alcanzó el tercer puesto (...). Aquel mismo año no concursó Silvana Mangano porque fue eliminada antes de llegar a candidata (...). El cine italiano de aquellos años se nutre de todas las misses del famoso 1947 y de algún otro año posterior a éste. En 1948 es Sophia Loren quien no se clasifica como Miss Italia, pero sí le es otorgado el premio Miss Elegancia" (Aranguren, 2003: 58).

2 Núria Bou titula un epígrafe de su libro "Plano/Contraplano", sugiriendo acertadamente que Crónica de un amor no es un filme con "mise en scène" sino con "mise en distance".

3 "Antonioni has shifted this periphery to the centre of things, has made the image a 'subject' in its own right: its shape, its colous, its movement, its time and the time of regarding it" (Rohdie 1992: 66). 
sexuales y se lo dice. "No pasa nada, son perlas baratas" responde ella. "¡Baratas! ¿Cuánto? ¿100.000?", dice un Guido indignado por el apunte burgués. Poco después encuentran el pendiente y los personajes se giran dando la espalda al espectador. Sus rostros quedan orientados hacía al vacío incapaces de mirarse a los ojos pese a que el diálogo posterior es especialmente íntimo. ${ }^{4}$ En este momento, queda claro que Antonioni intenta acercarse a los personajes desde todos los ángulos posibles: "El actor no aparece como un ídolo-fetiche, transmisor de las vicisitudes sentimentales del personaje (clasicismo), sino como un frío y complejo instrumento de la escritura autoral (...). No se prioriza la canalización de la subjetividad de los personajes (canon clásico), sino que se exacerba la subjetividad del autor" (Bou 2002: 115-116). Los dos personajes siguen estando solos pese a permanecer juntos y es el dinero lo que los separa.

Pese a ese indiscutible amor del cineasta moderno por las actrices ${ }^{5}$, Lucía Bosé no disfruta del primer plano clásico que convierte a la actriz en estrella. Su personaje no es especialmente positivo. Aunque el plan de asesinar al marido sea suyo, tampoco se puede decir que Paola sea una femme fatale al uso. Antonioni no estaba interesado en hacer una película de cine negro (no se resuelve el misterio de ninguna de las dos muertes que aparecen en pantalla ${ }^{6}$ ) del mismo modo que aunque la guerra aparezca todavía como trasfondo ("¿Acaso crees que es fácil matar a un hombre con un revolver? / ¿No estuviste en la guerra?"), ésta es una obra más preocupada por lo que sienten los personajes que por el contexto que crea esos sentimientos. El propio Antonioni aseguraba que "el neorrealismo ponía el acento sobre la relación existente entre el personaje y la realidad... Ahora que la realidad se ha normalizado para bien o para mal, me parece más interesante examinar lo que ha quedado en los personajes de sus experiencias pasadas. (....) Pienso que los hombres de cine deberían siempre estar ligados como inspiración a su tiempo, no tanto para expresarlo e interpretarlo en sus acontecimientos más crudos y trágicos cuanto para recoger sus resonancias dentro de nosotros. Me parece que es el único modo de estar vivos" (Declaraciones recogidas en Font, 2003: 50 y 271).

Tal y como asegura Marga Carnicé, se puede decir que la modernidad "apuesta por primera vez por la opacidad de la persona, por sus claroscuros interiores, por el deseo de devolver al cuerpo del actor su dimensión humana, proyectora de semejanzas espirituales, ya no ideales, con el espectador. No hay hacia él el interés de representación divina de la estrella, como tampoco el respeto contemplativo hacia el rostro anónimo de los realismos" (Carnicé, 2013: 2). El trabajo de Lucía Bosé en Crónica de un amor se lee en parte en estos términos: el neorrealismo acaba de dejar paso a la modernidad. El mito del actor-personaje se desvanece del mismo modo en que antes lo hizo el canon clásico del primer plano. La cámara recorre e inspecciona el cuerpo de los actores y estos se vacían de expresividad porque son los movimientos y los espacios los que definen su situación en el mundo y no ellos los que influyen en el escenario. La máscara del intérprete se construye en plano general.

4 "Guido, soy tan feliz./ Yo también. / ¡Cuantos años he deseado esto! / Siete años /Yo siempre te llevaba conmigo... ¡Siete años! Siempre me acordé de ti... aun casándome con otro mi amor eras tú... eras tú solo al qué quería".

5 "I specially love women. (...) Through the psychology of women everything becomes more poignant. They express themshelves better and more precisely. They are a filter which allows us to see more clearly and to distinguish things" (Declaraciones recogidas en Rohdie, 1992: 183)

6 "En cada film de Antonioni la búsqueda conduce al punto de partida, al "misterio" en suma, cuando precisamente el misterio por un proceso tautológico se ha disipado en el recorrido" (Font, 2003: 61). 


\section{LA SEÑORA SIN CAMELIAS}

Lucía Bosé es Clara Manni, una vendedora reconvertida en actriz de éxito que se casa con un empresario que, celoso, le prohíbe seguir actuando. Cuando ella insiste en su necesidad de trabajar, su marido monta y dirige una versión de Juana de Arco para que la protagonice, pero ésta es un fracaso y su decepción marital hace que acabe teniendo una aventura con un diplomático. A partir de entonces Clara se siente viva: está enamorada, estudia interpretación y rechaza papeles en películas de baja calidad para perseguir una consagración como actriz que nunca llega. Su amante no siente lo mismo por ella y Clara acaba intentando volver a los pies de un marido que la rechaza. Viéndose sin salida, Clara acepta trabajar en producciones de calidad ínfima y se reconcilia con el amante — pese a que éste no la quiere- acabando así totalmente destrozada, pero en movimiento.

Es fácil vislumbrar algunas similitudes entre el personaje de Clara y la propia Lucía Bosé: ambas eran dependientas que alcanzaron la fama debido a su belleza, mujeres de origen humilde que abrazaron la burguesía; ambas acabarán teniendo un marido anulador que haga que se alejen del mundo del cine. Giovana Grignaffini va más allá y propone una lectura de la actriz de cine italiano a través de esta fase de la carrera de Bosé:

Un trasferimento, una trasformazione, che non solo è resa narrativamente da due film ma é più profondamente agita dal suo percorso divistico a cavallo degli anni cinquanta: Dai concorsi di bellezza alla contadina di Non c’è pace tra gli ulivi, alla provinciale che si trasforma in ricca Borghese (Cronaca di un amore), alla commessa che diventa diva per poi ritrovarsi senza lavoro (La signora senza camelie). Lucía Bosé è l'immagine stesa di una mobilità geografica e sociale che trasforma il soggetto in una stratificazione di provenienze e appartenenze, Una stratificazione particolarmente legata all'universo femminile, strutturalmente connessa all'equazione bellezza-lavoro, il che significa passaggio obbligato attraverso il mondo del cinema o più in generale di un mondo ancora fondato sull'uso dell'immagine e del corpo (Giovana Grignaffini en Brunetta, 1996: 381).

Así como los personajes masculinos de Antonioni son, por lo general, seres fríos y dispersos, arrastrados por la inercia, Clara viene a reflejar la figura errante de la modernidad: "Antonioni's women protagonists were outsiders through alienation and neurosis" (Restivo, 2002: 101). Clara tiene éxito y todo lo que una chica debía desear, pero sus inquietudes impiden que vuelva a recuperar ese ímpetu y felicidad propio de la frescura e inocencia. La actriz aseguraba que "Antonioni fue el primer director que comenzó a trabajar con foto-flu. (...) por esta razón fue capaz de hacer aquellos fantásticos encuadres. Iluminaba todo el ambiente y, entonces la cámara se podía mover a su gusto. (...) ¡Qué planos tan impresionantes hacía! Una se queda admirada ante la facilidad que él tenía para ir por delante de su tiempo. (...) Lo que pasa es que él, trabajando, muchas veces te despertaba instintos criminales. Había escenas que repetíamos hasta cuarenta veces (...). Y es que, según él, cuanto más cansados estábamos los actores mejor salía la escena" (Aranguren, 2003: 59-60). Éste es precisamente el adjetivo que mejor define al personaje de Clara: cansada. Antonioni encierra al personaje femenino con el encuadre y el montaje y a la actriz con su dirección. Ya no se trata únicamente de registrar "el tema" (la enfermedad de los sentimientos) con la cámara, sino del confinamiento del mismo a través de la empresa cinematográfica: "By situating the woman as a product of the culture she observes, Antonioni asserts an interdependance between perceiving subject and 
the objet of perception. (...) For Antonioni the object of the cinema is inextricably bound to the constitution of the object world in relation to the perceiving subject" (Restivo, 2002: 102).

Cuando Clara y su marido estrenan su versión de Juana de Arco con una pésima recepción en el festival de Venecia, los comentarios de los asistentes van desde el "Después de la interpretación de la Bergman, ¿cómo se atreve?"7 al "Si con esa cara supiera actuar...". Clara decide replantearse su carrera cuando habla con su compañero de reparto y éste le indica que

ha tenido éxito casi sin trabajar. Probablemente no es culpa suya. Ha tenido directores mediocres, guiones inadecuados, no ha aprendido nada. Usted nunca ha conocido la mejor parte del cine italiano. Usted es bella y no han hecho más que fotografiar su belleza. Igual usted no puede hacer más o, en cambio, descubre en la carrera de actriz el sentido de su vida, pero esto aún no lo ha demostrado, ni a los demás, ni a sí misma. ¿Ha pensado en lo que supone ser una actriz seria? ¿Y de qué está hecho el éxito de los grandes actores? ¿Conoce todos los sufrimientos por los que ha tenido que pasar? ¿Y los largos años de estudio, de esperanzas y desilusiones? Hasta ahora el cine le ha dado una fama superficial. La ha metido en un mundo irreal y ahora siente que está vacío. Se puede decir que ni siquiera ha empezado a ser una actriz.

Este extracto de La señora sin camelias sorprende porque es tanto un discurso sobre Clara como sobre Lucía: la carrera de Bosé estaba bien orientada, pero, efectivamente, Antonioni no pretendía aprovecharse de los "sufrimientos por los que ha tenido que pasar". Con esta secuencia el director se desmarca explícitamente tanto del neorrealismo (hay un momento en que un personaje asegura que "iahora con esto del neorrealismo ruedan en cualquier sitio!") como de los métodos de aproximación autorales del movimiento: "El actor de cine no ha de comprender, ha de ser. Se me objetará que para ser necesita comprender. No. Si así fuera, el actor inteligente sería el mejor. La realidad nos demuestra a menudo lo contrario" (declaraciones de Antonioni recogidas en Font, 2003: 273).

Finalmente, Clara acepta trabajar en una película erótica de baja calidad porque "la juventud no es eterna". Lucía Bosé, por otro lado, se ofrece más a sí misma que a su cuerpo ante la cámara ya que "a través de ella, se han puesto en evidencia la belleza de unos rasgos limitados en las posibilidades, las debilidades y también la temporalidad de lo humano. Ese cuerpo tiene consciencia de lo previamente representado por sí mismo. En esa consciencia, compartida con el espectador, nace otra historia del cine, otra galería de imágenes en las que podríamos citar muchos encuentros" (Carnicé, 2013: 3). La relación Antonioni-Bosé supone el primer encuentro del realizador con una actriz como ente manipulable. Aquí nunca se trató de extraer la realidad ni el mito actor, sino el objeto o, si se quiere, el "meta-objeto". Es curioso, sin embargo, que el encuentro no distase tanto de esas otras relaciones personales actriz-director que tanto influyeron en el cine italiano anterior y posterior. Bosé recuerda: "Mi boda dio pie a una reacción absurda por parte de Antonioni. Inexplicablemente, como yo era su "musa" en aquel momento, dejó de dirigirme la palabra durante diez años. Su reacción me pareció tan extraña, tan exagerada, que pudo, en su momento, resultarme incluso halagadora" (Aranguren, 2003: 70-71).

7 Ingrid Bergman llegó a protagonizar dos películas basadas en la historia de Juana de Arco: Joan of Arc (Victor Fleming, 1948) y Giovanna d'Arco al rogo (Roberto Rossellini, 1954).

8 La actriz sugiere un sentimiento similar en Juan Antonio Bardem: "A Bardem le cayó fatal que me casara con el torero: Ese hombre no te conviene - me decía" (ARANGUREN, 2003: 70). 


\section{MUERTE DE UN CICLISTA}

Lucía Bosé es María José, una mujer casada con un rico empresario que tiene a su vez una aventura con Juan, su antiguo novio. María José no esperó a que Juan volviera de la guerra y se casó. En una de sus escapadas amorosas, ella atropella a un ciclista y lo dejan morir. Rafael sabe de su relación y se dedica a chantajearles, aunque finalmente no consigue nada. Juan conoce a Matilde, una de sus alumnas, y su juventud y carácter idealista hacen que decida tomar las riendas de su vida y confesar el homicidio. María José no lo permite y atropella a Juan para, acto seguido, morir en un accidente de tráfico. Un ciclista que pasa por allí, y es en parte culpable del accidente, escapa sin avisar a nadie de la muerte, cerrando así el círculo.

En palabras de Doménec Font (2003: 102), Muerte de un ciclista es una película que vive de las rentas de Crónica de un amor. El propio Bardem reconoce que había tenido la ocasión de ver la película en la Semana de Cine Italiano de 1953 y que fue una de las razones por las que persiguió a Bosé para el papel. ${ }^{9}$ Las dos películas presentan varias similitudes: la mujer provinciana convertida en burguesa, la relación extramarital con un novio del pasado, la muerte que actúa como unión y desunión en la relación con el amante, etc. Sin embargo, lo que en Antonioni es una interiorización en los personajes a través de la forma, aquí se convierte en un discurso sobre la España de la dictadura a través de las reglas y el formato del cine negro clásico. Otra de las diferencias sustanciales a la hora de aproximarse al mismo tema es la necesidad de incluir un villano y la de finalizar el relato con un veredicto moral que juzga a los personajes: los dos protagonistas, asesinos e infieles, tienen que morir. Ese final no fue impuesto por la censura española; curiosamente, fueron los organismos italianos (la película es una coproducción) los que mostraron reservas ante el trasfondo político-social. ${ }^{10}$

El protagonista de Muerte de un ciclista es un héroe que vaga por la historia afligido y agotado. María José, sin embargo, asume un rol masculinizante ya que comparte con él "el valor objetual de su relación clandestina (...) El personaje femenino posee unos criterios más firmes y definidos que el héroe, lo que la sitúa en una posición privilegiada para dirigir el avance de la acción" (Pérez Rufi, 2007). Al retratar un arquetipo masculino desprovisto de energía, ella es la que decide en todo el relato (primero, obligando a escapar del lugar del accidente; finalmente, asesinando a su amante). A diferencia de Antonioni, que no juzga, Bardem convierte a Lucía Bosé en la femme fatale clásica: "En un espacio en el que no hay lugar para el héroe solar, la figuración femenina toma la iniciativa en el relato" (Bou, 2001).

Muerte de un ciclista se ha leído acertadamente como una película crítica con el sistema y eso queda reflejado en la concepción de varias secuencias. Por ejemplo, Juan será atropellado por María José en la misma carretera donde tuvo lugar el primer accidente: "El

9 La actriz reconoce que aceptó participar en la película porque acababa de sufrir un desengaño amoroso y el trabajo suponía alejarse de todo viajando a España donde, casualmente, acabaría conociendo a Dominguín.

10 "No deja de ser paradójico que la estrategia de la coproducción, que tenía como una de sus virtudes la de la ampliación de la libertad expresiva del director al establecerse con países democráticos, tuviese como efecto la represión sobre ciertos aspectos político-sociales del filme. En todo caso, este episodio coincide con las dificultades que por aquel entonces atravesaba en Italia el cine neorrealista" (Cerón Gómez, 1999). Ciertamente lo que se ponía en juego no era una vaga condena del egoísmo (como apunta el título italiano de la cinta, Gli egoisti) ni un mero proceso de regeneración personal tras la comisión de un homicidio involuntario. De lo que se trataba era de mostrar cómo una clase social había sido la beneficiaria de un conflicto bélico y de cómo algunos de sus miembros tomaban conciencia de la injusta situación creada" (Cerón Gómez, 2000).

Quaderns, 8 (2013), pp. 73-80 
protagonista afirma sentirse ligado con el escenario en el que se cometió el atropello de la primera escena. Además del trágico crimen que lo unirá a éste para siempre en la última secuencia, Juan combatió allí durante la Guerra Civil (Pérez Rufi, 2007). La diferencia con Crónica de un amor es que esos espacios no pretenden hablar de los personajes a través del encuadre, sino que se limitan a describir acontecimientos y exponer el contexto histórico.

El acercamiento a los actores y a las relaciones que se establecen entre ellos se realiza casi siempre en planos medios o, como en su secuencia más famosa (la del espectáculo flamenco), en primeros planos repletos de miradas subrayadas que dirigen la atención del espectador hacia la trama. Curiosamente, el mecanismo que más aleja la película de Bardem del cine clásico no está dentro del plano sino en los márgenes: el montaje de la película reúne de manera continua diversos marcos y personajes a través de la técnica del Match cut. Uno de los ejemplos más representativos es el momento en que Rafael, el chantajista, lanza una botella con rabia hacía el vacío. El siguiente plano será el de una ventana rompiéndose por el impacto, pero el tercero nos mostrará que hemos cambiado de espacio y nos encontramos ante una manifestación estudiantil en la universidad donde trabaja Juan. Bardem juega así a la confusión con el corte de imágenes y sonidos, pero incluso aquí lo utiliza para describir un proscenio a medio camino entre el filme y la realidad social del mismo.

En esta ocasión, la figura de Lucía Bosé es usada como referente. Por un lado, hacia el personaje de Paola en Crónica de un amor; por otro hacia la mujer fatal arquetípica del cine negro; ${ }^{11}$ finalmente, hacía el retrato de los síntomas del contexto social de un país. A diferencia de Paola, la María José de Lucía Bosé supera la representación haciendo estallar sus límites y extendiendo la película a otros territorios. Lucía Bosé es más actriz en el sentido clásico que nunca, pero Bardem no la somete tanto a la representación como a la presentación.

\section{APUNTE FINAL}

Tal y como explica la famosa cita de Greta Garbo, "being a movie star, and this applies to all of them, means being looked at from every possible direction. You are never left at peace, you're just fair game". La condición de estrella de Lucía Bosé es cuestionable ${ }^{12}$ entre otras cosas porque fue una actriz que prefirió la vida doméstica a la vida filmada, pero no lo es así su pertenencia al estrellato transnacional.

Lucía Bosé se despidió del cine, ya embarazada de su primer hijo, en Así es la aurora (1956). La última imagen del filme mostraba un plano general en el que desaparecía felizmente en la lejanía. El plano de su reaparición en Nocturno 29 (1968), doce años después, la mostraba irrumpiendo tras una esquina en un largo plano de seguimiento donde acabaría fundiéndose con la luz de un ventanal que quemaba el celuloide. Hoy, en perspectiva, podemos decir que fue modelada y utilizada por, entre otros, Giuseppe de Santis, Luis Buñuel,

11 Es necesario destacar que la voz de Bosé en Muerte de un ciclista está doblada por Elsa Fábregas, actriz que también fue la voz de grandes féminas del cine clásico de Hollywood como Rita Hayworth en Gilda (Charles Vidor, 1946), Lauren Bacall en Cayo Largo (Key Largo. John Huston, 1948), o Gloria Swanson en El crepúsculo de los dioses (Sunset Boulevard. Billy Wilder, 1950).

12 Francesco Alberoni destaca que las condiciones esenciales para el fenómeno de la estrella son las siguientes: 1) Un estado de derecho. 2) Una burocracia eficaz. 3) Un sistema social estructurado. 4) Una sociedad a gran escala. 5) Desarrollo económico superior al nivel de subsistencia. 6) Movilidad social (Alberoni en Dyer, 2001: 20-21). Según esta categorización una actriz en la España de los 50 nunca podría llegar a ser estrella. 
Pere Portabella, Basilio Martín Patino, Jean Cocteau, Federico Fellini, Marguerite Duras, Paolo y Vittorio Taviani, Agustín Villaronga, e incluso Luís Miguel Dominguín.

A través de los ejemplos de Antonioni y Bardem se ha intentado exponer que el lenguaje de la intérprete, más allá del idioma o el método de actuación, es uno externo a ella misma: es el de la puesta en escena. Desde el plano general bajo un pórtico en el que Paola es abandonada, hasta la muerte de María José en contrapicado, pasando por la sonrisa forzada de Clara ante los flashes de los periodistas, Lucía Bosé dejó de pertenecerse a sí misma desde el momento en que Visconti le aseguró que era carne de cine.

\section{BIBLIOGRAFÍA}

ARANGUREN, Begoña. Lucía Bosé. Diva divina. Barcelona, Planeta, 2003.

BOU, Núria. Epifanies de la passió: els films de Michelangelo Antonioni. Barcelona, 1994 (Treball de recerca)

- "Retrato nocturno de la femme fatale" en Formats, n 3 (2001). Barcelona, Universidad Pompeu Fabra.

- Plano/Contraplano. De la mirada clásica al universo de Michelangelo Antonioni. Barcelona, Biblioteca Nueva, 2002.

BRUNETTA, Gian Piero. Identità italiana e identità europea nel cinema italiano dal 1945 al miracolo economico. Torino, Fondazione Giovanni Agnelli, 1996

CAMERON, Ian. "Michaelangelo Antonioni", Film Quarterly, Vol. 16, № 1 (1962), pp. 1-58.

CARNICÉ MUR, Margarida. Dolor de actriz: Anna Magnani en la invención del cine moderno. Barcelona, 2013 (treball de recerca).

CAUSO, Massimo y LA MONICA, Alberto. Lucía Bosé. Vita Cinema Luce. Lecce, Festival del cinema europeo, 2006.

CERÓN GÓMEZ, Juan Francisco. "El cine de Juan Antonio Bardem y la censura franquista (1951-1963): las contradicciones de la represión cinematográfica", Imafronte, n 14 (1999), pp. 23-36.

- "Las paradojas de la censura: Muerte de un ciclista (1955), de Juan Antonio Bardem". En Actas del VII Congreso de la A.E.H.C., Madrid, Academia de las Artes y Ciencias Cinematográficas de España, 1999, pp. 125-140.

DYER, Richard. Las estrellas cinematográficas. Barcelona, Paidós, 2001.

FONT, Doménec. Michelangelo Antonioni. Madrid, Cátedra, 2003.

OLANO, Antonio D. Estrellas y stars. Barcelona, Dopesa, 1974.

ORBAN, Clara. "Antonioni's Women, Lost in the City", Modern Language Studies, Vol. 31, N. 2 (2001), pp. 11-27.

PÉREZ RUFÍ, José Patricio. "La construcción narrativa del personaje en el cine de Bardem", Frame, Nº 2 (2007), págs. 130-153

RESTIVO, Angelo. The cinema of economic miracles. Estados Unidos, Duke University Press, 2002.

ROHDIE, Sam. Antonioni. Londres, British Film Institute, 1992.

TORRES, Casimiro (1997): "Muerte de un ciclista", en PÉREZ PERUCHA, Julio (ed.): Antología del cine español: 1906-1995: flor en la sombra. Madrid, Cátedra, pp. 362-364.

VENTURI, Lauro. "Notes on Five Italian Films", Hollywood Quarterly, Vol. 5, No. 4 (1951), pp. 389-400. 